\title{
Neurodegenerative diseases among miners in Ontario, Canada, using a linked cohort
}

\author{
Xiaoke Zeng ${ }^{10}{ }^{1,2}$ Nathan L DeBono, ${ }^{1,2}$ Anne M Harris, ${ }^{1,3}$ Victoria H Arrandale, ${ }^{1,2}$ \\ Paul A Demers ${ }^{1,2}$
}

- Additional material is published online only. To view, please visit the journal online (http://dx.doi.org/10.1136/ oemed-2020-106958).

${ }^{1}$ Occupational and Environmental Health Division, University of Toronto, Toronto, Ontario, Canada

${ }^{2}$ Occupational Cancer Research Centre, Ontario Health, Toronto, Ontario, Canada

${ }^{3}$ School of Occupational and Public Health, Ryerson University, Toronto, Ontario, Canada

\section{Correspondence to}

Xiaoke Zeng, Occupational and Environmental Health Division, University of Toronto, Toronto, ON M5S, Canada; xiaok.zeng@gmail.com

Received 4 August 2020 Revised 21 October 2020 Accepted 3 November 2020 Published Online First 24 November 2020
Check for updates

(C) Author(s) (or their employer(s)) 2021. No commercial re-use. See rights and permissions. Published by BMJ.

To cite: Zeng $X$,

DeBono NL, Harris AM,

et al. Occup Environ Med

2021:78:385-392

\section{ABSTRACT}

Objectives We examined employment in mining occupations and industries and its association with neurological disease incidence in a linkage cohort from Ontario, Canada. Outcomes included Alzheimer's disease (alone and with other dementias), Parkinson's disease, parkinsonism, motor neuron disease and amyotrophic lateral sclerosis (ALS).

Methods The Occupational Disease Surveillance System cohort was created by linking workers' compensation data and healthcare usage records. This analysis included over 1.1 million male workers, followed between 1999 and 2016. Neurological diseases were ascertained using physician billing and hospital discharge records. Adjusted Poisson regression models were used to estimate incidence rate ratios (RR) comparing mining to non-mining workers overall and by ore (industry) and occupation group.

Results Suggested elevations in incidence rates were observed for ALS among workers of metal mines (RR $2.21,95 \% \mathrm{Cl} 1.04$ to 4.69 ) and for motor neuron disease among those employed in mining occupations within metal mining industries (RR 1.96, 95\% Cl 1.01 to 3.79), though these were based on relatively few cases. In miscellaneous metal mines, workers who held mining occupations had an elevated rate of Alzheimer's disease (RR 1.27, 95\% Cl 0.92 to 1.77). Parkinson's disease rate was elevated among workers with rock and soil drilling occupations (RR 1.60, 95\% Cl 1.04 to 2.45).

Conclusions Mining hazards may be associated with elevated rates of neurodegenerative diseases among workers in mining occupations and industries. More work is needed to better understand mining exposures and their associations with neurodegenerative diseases.

\section{INTRODUCTION}

The prevalence of neurological conditions, especially neurodegenerative disease, has been increasing over the past few decades. ${ }^{1}$ The economic burden for these conditions in Canada has been substantial and estimated to be in the billion-dollar range for dementias and hundreds of millions for parkinsonism and motor neuron disease. ${ }^{2}$ Commonly known neurodegenerative diseases include Alzheimer's disease, Parkinson's disease and amyotrophic lateral sclerosis (ALS).

Identifying risk factors for progressive neurological diseases and working populations at risk is crucial to proposing avenues for prevention; studying workers with high exposure levels has proven to be a valuable approach. ${ }^{3}$ Frequently

\section{Key messages}

What is already known about this subject?

- Neurodegenerative disease incidence is increasing worldwide with significant costs. Several workplace exposures are potential risk factors of neurodegenerative diseases such as diesel engine exhaust and aluminum; while these exposures are common, occupational exposures (such as those experienced in mining occupations) are much higher.

\section{What are the new findings?}

- Workers in metal mines had suggested elevated incidence rates of motor neuron disease. Gold and miscellaneous metal (primarily nickelcopper and zinc ores) miners had a suggestive elevation in Alzheimer's or Parkinson's disease rates.

How might this impact on policy or clinical practice in the foreseeable future?

- Our findings may provide evidence to support the review of workers' compensation claims for neurodegenerative conditions among miners in Ontario.

studied risk factors and occupation groups at risk for neurodegenerative diseases include (1) electromagnetic fields exposure among workers in electrical occupations; (2) pesticide exposure among farmers, plantation workers and gardeners and (3) heavy metals such as lead exposure among workers who handle lead-containing materials, fumes, dust or liquids. ${ }^{4}$

Mining work has long been recognised as a hazardous occupation due to the risk of injury ${ }^{5}$ and exposure to known carcinogens and respiratory hazards such as diesel engine exhaust. ${ }^{67}$ Several Canadian studies have reported general population prevalence and incidence rates for Alzheimer's disease and other dementias, ${ }^{8}$ Parkinson's disease, ${ }^{9}$ parkinsonism ${ }^{10}$ and ALS, ${ }^{11}$ during different calendar periods, but incidence rates of neurodegenerative diseases incidence in mining workers have not yet been examined.

The province of Ontario, Canada, has over 200 years of mining history. Gold, nickel and uranium are three primary ores among various minerals mined in Ontario. ${ }^{12}$ Tens of thousands of workers have been annually employed at Ontario's mines 
and metallurgical sites over the last century. ${ }^{13} 14$ Using a linkage cohort, the Occupational Disease Surveillance System (ODSS) cohort, the objective of this study is twofold. The first is to describe age-standardised incidence rates for multiple neurodegenerative outcomes among Ontario miners between 1999 and 2016, including Alzheimer's disease, 'Alzheimer's and other dementias', Parkinson's disease, parkinsonism, motor neuron disease and ALS. The second is to estimate incidence rate ratios (RRs) for each neurodegenerative disease among workers in mining industries and occupations compared with workers in other industries and occupations.

\section{METHODS}

\section{Study population and employment in mining}

The ODSS cohort was described in detail previously. ${ }^{15}$ Briefly, the ODSS was established by linking workers' compensation lost-time claimant data (1983-2014), held by the Workplace Safety and Insurance Board (WSIB) of Ontario, to administrative databases of healthcare usage to allow the ascertainment of health outcomes. Workers in the ODSS cohort had at least one accepted lost-time workers' compensation claim. A subcohort of the ODSS cohort was used to construct the present study cohort, the ODSS health insurance number (HIN) cohort, which included only individuals ( $\mathrm{n}=1805$ 957) with HINs. The ODSS HIN cohort has previously been used to describe the risk of dermatitis among industry and occupation groups in Ontario. ${ }^{16}$ The present study cohort included 1230349 male workers whose age at first claim date was 15 years and above (online supplemental material, figure S1). Female workers were not included in our study cohort due to the rarity of neurodegenerative disease cases $(<5)$ among the relatively small numbers of female workers employed in mining industries or occupations.

According to the Canadian Classification Dictionary of Occupations criteria (CCDO-1971) ${ }^{17}$ and Canadian Standard Industry Classification criteria (SIC-1970), ${ }^{17}$ workers' occupation and industry at the time of the claim were coded by WSIB at minor, major and division levels. Workers in mining industries were identified as those who had at least one claim using the SIC division level code 04 for 'Mines (including Milling), Quarries and Oil Wells.' Similarly, workers who held a mining occupation referred to those who had at least one claim with the CCDO division level code 77 for 'Mining and Quarrying, including Oil and Gas Field Occupations.' Workers in mining industries (and its subgroups) and occupations (and its subgroups) were independently identified by industry and occupation classification, respectively. We also crossexamined to extract other subgroups of workers within mining industries who held mining occupations (CCDO code 77) (online supplemental material, table S1).

\section{Outcome ascertainment}

Canada's single-payer healthcare system provides coverage for all citizens and permanent residents. Ontario administrative health databases, including Discharge Abstract Database (DAD), National Ambulatory Care Reporting System (NACRS) and Ontario Health Insurance Plan Claims Database (OHIP), were used to ascertain neurodegenerative outcomes in this study. These three databases are described in detail in Health Analyst's Toolkit ${ }^{18}$ and are briefly described below. DAD records contain clinical and demographic information on hospital discharges. NACRS records contain ambulatory care data, including day surgery, outpatient and community-based clinics and emergency departments. Diagnoses in DAD and NACRS are coded using the International Classification of Disease, 10th Revision, Canadian Modification (ICD-10). ${ }^{19}$ OHIP records contain healthcare provider billing records, and OHIP diagnoses are coded using a modified version of ICD $-9,{ }^{20}$ and coding is limited to three digits.

Case definitions for each outcome are presented in table 1 . At least one record with corresponding diagnostic codes from hospital discharge or ambulatory care data or at least two physician claims within 12 months was used to ascertain 'Alzheimer's and other dementias' and parkinsonism. This case definition achieved an average of about $70 \%$ in both positive predictive value and sensitivity from validation studies on case ascertainment algorithms of the same outcomes using Ontario administrative health databases. ${ }^{810}$ 'Alzheimer's and other dementias' and parkinsonism were examined as outcome groups. Alzheimer's disease, Parkinson's disease, motor neuron disease and ALS were ascertained by at least one record with a corresponding diagnostic code from hospital discharge or ambulatory care data.

We decide to involve physician billing records (OHIP) to ascertain group outcomes-'Alzheimer's and other dementias' and parkinsonism-but not for other outcomes due to OHIP diagnostic codes' inability to differentiate these other outcomes. For example, the OHIP code 331 denotes other cerebral degenerations, which includes Alzheimer's disease, but Alzheimer's disease cannot be differentiated from the code $331 .^{20}$

Table 1 Definitions used to ascertain Alzheimer's disease, Parkinson's disease, motor neuron disease, amyotrophic lateral sclerosis, Alzheimer's and other dementias, and parkinsonism in this study

\begin{tabular}{|c|c|c|c|}
\hline & $\begin{array}{l}\text { Diagnostic codes in DAD and NACRS } \\
(\text { ICD-10-CA })^{19}\end{array}$ & Diagnostic codes in $0 \mathrm{OH}^{20}$ & \\
\hline Neurodegenerative disease & $\begin{array}{l}\text { Disease follow-up period: } \\
1 \text { January } 2006 \text { to } 31 \text { December } 2016\end{array}$ & $\begin{array}{l}\text { Disease follow-up period: } \\
1 \text { January } 1999 \text { to } 31 \text { December } 2016\end{array}$ & Case definition \\
\hline Alzheimer's disease & $\mathrm{G} 30$ & - & \multirow{4}{*}{$\begin{array}{l}\text { At least one record with one diagnostic code in } \\
\text { any diagnostic field in DAD or NACRS }\end{array}$} \\
\hline Parkinson's disease & $\mathrm{G} 20$ & - & \\
\hline Motor neuron disease & $\mathrm{G} 12.2$ & - & \\
\hline Amyotrophic lateral sclerosis & G12.20 & - & \\
\hline 'Alzheimer's and other dementias' & F00, F01, F02, F03, G30 & 290,331 & \multirow{2}{*}{$\begin{array}{l}\text { At least one record with one diagnostic code } \\
\text { in any diagnostic field in DAD or NACRS or at } \\
\text { least two physician encounters with at least one } \\
\text { diagnostic code in OHIP within } 12 \text { months }\end{array}$} \\
\hline Parkinsonism & G20, G21.0-0.4, G21.8-9, G22, F02.3 & 332 & \\
\hline
\end{tabular}

The OHIP code 290 refers to dementia, and code 331 denotes to other cerebral degenerations, which includes Alzheimer's disease, but Alzheimer's disease cannot be differentiated from code $331 .^{20}$

DAD, Discharge Abstract Database; NACRS, National Ambulatory Care Reporting System; OHIP, Ontario Health Insurance Plan Claims Database; ICD-10-CA: International Statistical Classification of Diseases and Related Health Problems, Tenth Revision.; 
Likewise, the OHIP code 332 is documented as 'Parkinson's disease' in Ontario's resources' manual for physicians, ${ }^{20}$ but our data linkage showed records of both Parkinson's disease and secondary parkinsonism included under this code.

\section{Statistical analysis}

Workers in the ODSS cohort were enrolled between 1983 and 2014 and the follow-up period for health outcomes spanned from 1999 to 2016 (online supplemental material, figure S2). The start of follow-up for each neurodegenerative outcome was set as the latest date between the first accepted compensation claim date and the start date of administrative databases (1 January 1999, for OHIP and 1 January 2006, for DAD and NACRS). As the ALS diagnostic code (ICD-10-CA, G12.20) did not appear in DAD and NACRS until 2012, the database start date of 1 January 2012 was set for ALS.

Workers were followed up until the diagnosis of a particular disease of interest, death, emigration out of province, age 100 years, or end of the study period (31 December 2016), whichever occurred first. At the end of follow-up, age was censored at 100 years to minimise bias due to loss of follow-up. In different subcohorts for each neurodegenerative outcome (online supplemental material, figure S1), the number of cohort members age censored was between 47 and 58 ( $<0.01 \%$ of cohort). Prevalent cases of each neurological outcome are defined as individuals who met the disease ascertainment at any point before entry into follow-up, which were excluded. Incident cases are defined as individuals who met the case definition after their follow-up start date. Exclusions were also applied to workers who never made to the start of follow-up due to death, emigration, or age censoring. These exclusions resulted in varying total numbers of workers eligible for disease follow-up in different subcohorts for each neurodegenerative outcome.

Incidence rates of each neurodegenerative disease were directly age standardised to the 2011 Ontario male population ${ }^{21}$ for workers in the study cohort and workers of mining industries and occupations. Incidence RRs and 95\% CIs were estimated using Poisson regression models for each neurodegenerative disease for workers in mining industries and mining occupations (and their subgroups), with the referent being workers in non-mining industries and occupations. In the ODSS cohort, the major non-mining industries regarding the total number of workers are Manufacturing, Community, Business and Personal Services, Trade, Public Administration and Defence, Transportation, Communication and other Utilities, and Construction. RRs were adjusted for attained age, age ${ }^{2}$ and birth year throughout the follow-up period as confounders in the age-period-cohort analysis that could associate with employment in mining and neurodegenerative outcomes. Various covariate specifications for age and birth year adjustment were explored, and final model specifications were chosen based on model fit statistics (Akaike information criterion) and consideration of model parsimony. All analyses were performed using SAS V.9.4 (SAS Institute).

\section{RESULTS}

The number of mining workers eligible at the start of follow-up varied depending on the outcome due to data availability for follow-up (table 2 and online supplemental material, figure S1). Median years of follow-up were longer for subcohorts of Alzheimer's and other dementias and parkinsonism (18 years) but shorter for ALS (5 years) due to limited data availability where coding could identify ALS. Cohort members employed in mining industries or occupations in this study had a median birth year around 1954 and a median age at the end of follow-up around 62 , while cohort members in non-mining industries or occupations were 6 years younger (table 2).

The majority of workers in mining industries worked at metal mines, including uranium mines (9\%), gold mines (11\%) and miscellaneous metal mines (41\%) (table 2). Based on available information on the specific mines of workers in the present cohort, miscellaneous metal mines comprised approximately $78 \%$ nickel, $13 \%$ zinc and $9 \%$ other ores. About 60\%-70\% of workers from metal ore mines held mining occupations, whereas only $26 \%-28 \%$ of workers in non-metal industries held mining occupations. The most common mining occupations were cutting, handling, and loading (37\%), rock and soil drilling $(25 \%)$, and other mining and quarrying work (33\%).

\section{Age-standardised Incidence rates for Alzheimer's-related outcomes}

'Alzheimer's and other dementias' (1999-2016) showed the highest age-standardised incidence rate of approximately 319 cases per 100000 person-years, whereas the incidence rate for Alzheimer's disease (2006-2016) was 43 cases per 100000 person-years (table 3). Workers in mining occupations were observed with a higher incidence rate of Alzheimer's disease than workers in non-mining occupations (53 vs 43 cases per 100000 person-years).

\section{Age-standardised incidence rates for Parkinson's-related outcomes}

In the study cohort, a higher incidence rate was observed for parkinsonism (1999-2016) than Parkinson's disease (20062016) (53 vs 35 cases per 100000 person-years) (table 3). Workers of mining industries or occupations had slightly higher incidence rates of Parkinson's disease but lower incidence rates of parkinsonism than workers in non-mining industries or occupations.

\section{Age-standardised incidence rates for motor neuron disease}

The incidence rate for both motor neuron disease (2006-2016) and ALS (2012-2016) was around 4 cases per 100000 personyears among workers in this cohort, and the rates for workers in mining industries and occupations were higher than rates among non-miners.

\section{Incidence RRs for Alzheimer's-related outcomes}

Elevated rates of Alzheimer's disease were observed for workers in miscellaneous metal mines who held mining occupations (RR $1.27,95 \% \mathrm{CI} 0.92$ to 1.77 ) compared with workers in nonmining industries (table 4). Suggested elevations in Alzheimer's disease (RR 1.49, 95\% CI 0.88 to 2.52) and 'Alzheimer's and other dementias' (RR 1.10, 95\% CI 0.91 to 1.33 ) were observed for workers in gold mines. Work in mining occupations was associated with an elevated rate of Alzheimer's disease (RR 1.28, $95 \%$ CI 0.98 to 1.66) compared with workers in non-mining occupations (table 4).

\section{Incidence RRs for Parkinson's-related outcomes}

Compared with workers in non-mining occupations, the rate for Parkinson's disease was elevated for workers in rock and soil drilling occupations (RR 1.60, 95\% CI 1.04 to 2.45); $66 \%$ of these cases (14 out of 21 ) occurred among workers in miscellaneous metal mines (table 4). Compared with workers in non-mining industries, suggested elevations in rates of Parkinson-related conditions were observed for workers within 
Table 2 Characteristics of workers in mining occupations and industries (1983-2016) by disease follow-up spanning from 1999 to 2016 in the study cohort

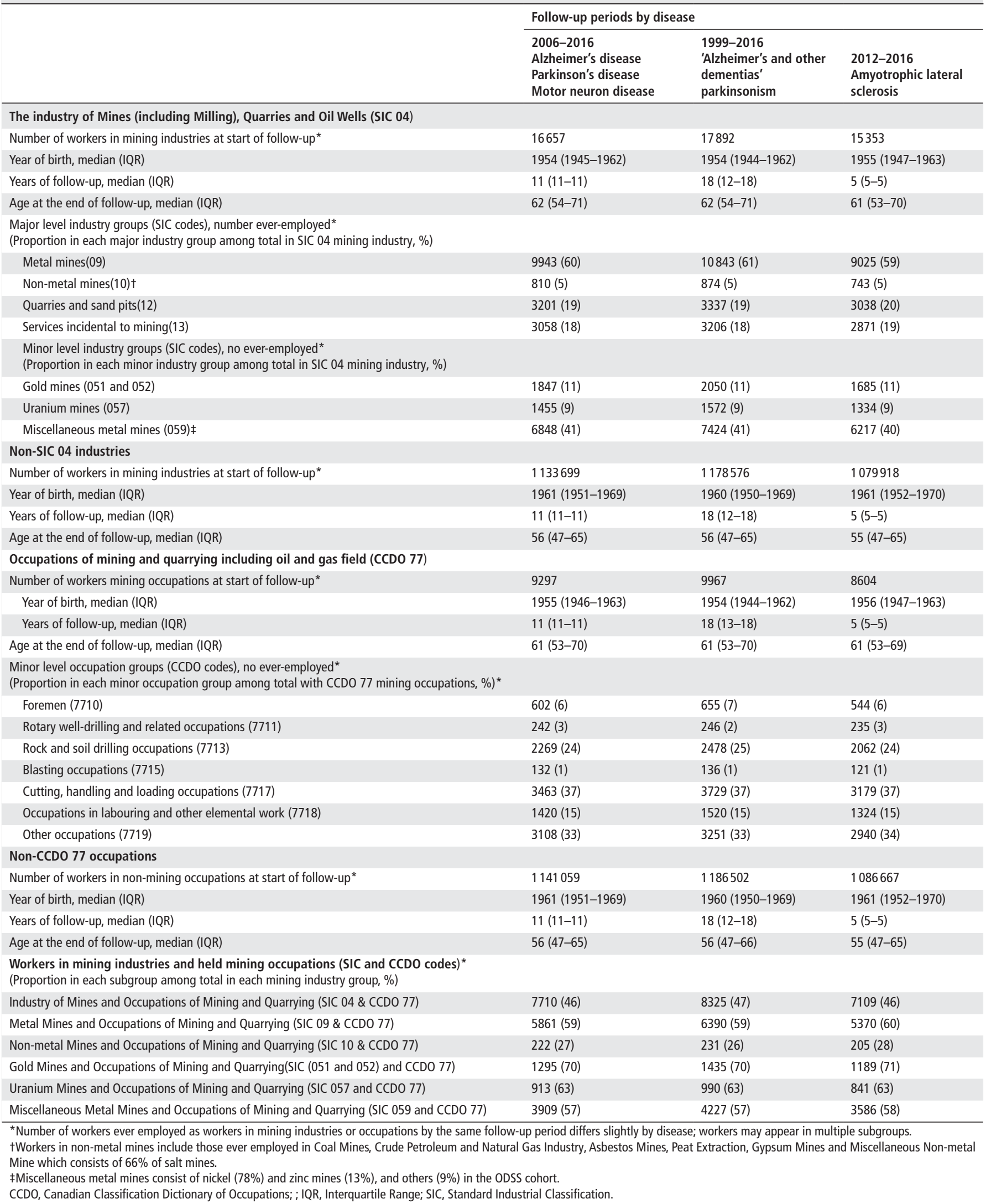

gold mines who held mining occupations (Parkinson's disease RR 1.43, 95\% CI 0.72 to 2.86; Parkinsonism RR 1.25, 95\% CI 0.78 to 2.01 ). Workers in non-metal mines also had a suggested elevation in Parkinsonism (RR 1.95, 95\% CI 1.19 to 3.18); however, most cases that contributed to this elevation were from workers who did not hold mining occupations. 
Table 3 Direct age-standardised incidence rates per 100000 person-years for neurodegenerative conditions among workers in the study cohort, standardising to the 2011 Ontario male population

\begin{tabular}{|c|c|c|c|c|c|c|}
\hline Study population & $\begin{array}{l}\text { Alzheimer's } \\
\text { disease } \\
(2006-2016)\end{array}$ & $\begin{array}{l}\text { 'Alzheimer's and } \\
\text { other dementias' } \\
(1999-2016)\end{array}$ & $\begin{array}{l}\text { Parkinson's } \\
\text { disease } \\
(2006-2016)\end{array}$ & $\begin{array}{l}\text { Parkinsonism } \\
(1999-2016)\end{array}$ & $\begin{array}{l}\text { Motor neuron } \\
\text { disease } \\
(2006-2016)\end{array}$ & $\begin{array}{l}\text { Amyotrophic } \\
\text { lateral sclerosis } \\
(2012-2016)\end{array}$ \\
\hline Total workers in the study cohort & 42.9 & 319.1 & 34.6 & 53.2 & 4.3 & 3.6 \\
\hline Workers in non-mining industries & 43.0 & 319.3 & 34.5 & 53.2 & 4.3 & 3.5 \\
\hline $\begin{array}{l}\text { Workers in industry of mines (including milling), } \\
\text { quarries and oil wells (SIC 04) }\end{array}$ & 40.8 & 305.5 & 38.5 & 51.6 & 5.2 & 6.3 \\
\hline Workers in non-mining occupations & 42.9 & 319.5 & 34.5 & 53.2 & 4.3 & 3.6 \\
\hline $\begin{array}{l}\text { Workers in occupations of mining and quarrying, } \\
\text { including oil and gas field (CCDO 77) }\end{array}$ & 53.0 & 294.0 & 40.9 & 50.8 & 5.5 & 4.9 \\
\hline
\end{tabular}

Alzheimer's disease: At least one record with one diagnostic code (ICD10: G30) in any diagnostic field in DAD or NACRS.

Alzheimer's and other dementias: At least one record with one diagnostic code (ICD-10 F00, F01, F02, F03, G30) in any diagnostic field in DAD or NACRS or at least two physician encounters with at least one diagnostic code in OHIP (OHIP code 290, 331) within 12 months.

Parkinson's disease: At least one record with one diagnostic code (ICD10: G20) in any diagnostic field in DAD or NACRS.

Parkinsonism: at least one record with one diagnostic code ICD-10 G20, G21.0-0.4, G21.8-9, G22, F02.3 in any diagnostic field in DAD or NACRS or at least two physician encounters with at least one diagnostic code in OHIP (OHIP code 332) within 12 months.

Motor neuron disease: At least one record with one diagnostic code (ICD10: G12.2) in any diagnostic field in DAD or NACRS.

Amyotrophic later sclerosis: At least one record with one diagnostic code (ICD10: G12.20) in any diagnostic field in DAD or NACRS.

CCDO, Canadian Classification Dictionary of Occupations; DAD, Hospital Discharge Abstract Database; ICD-10, International Classification of Disease, 10th Revision; NACRS,

National Ambulatory Care Reporting System; OHIP, Ontario Health Insurance Plan Claims Database; SIC, Standard Industrial Classification.

\section{Incidence RRs for motor neuron disease}

Elevated rates were suggested for motor neuron disease among workers in metal mines (motor neuron disease RR 1.62, 95\% CI 0.94 to 2.81; and ALS RR 2.21, 95\% CI 1.04 to 4.69) and workers within metal mines who held mining occupations (RR 1.96 , 95\% CI 1.01 to 3.79 ), compared with workers in nonmining industries or occupations (table 5).

\section{DISCUSSION}

Within this cohort, miners showed higher incidence rates for Alzheimer's, Parkinson's and motor neuron disease than nonminers. Elevated rates of motor neuron disease and ALS were suggested for workers in metal mines, but there were relatively few cases. The rate of Alzheimer's disease was elevated for workers within miscellaneous metal mines who held mining occupations. Workers in gold mines and their subgroup who had mining occupations had suggestive elevations for Alzheimer's or Parkinson's-related outcomes. An elevated rate of Parkinson's disease was also observed among workers who held rock and soil drilling occupations.

Age-standardised incidence rates for 'Alzheimer's and other dementias', parkinsonism and ALS are at a similar magnitude to other findings from Ontario studies on incidences. Jaakkimainen et al reported an age and sex adjusted incidence rate of 18 per 1000 persons for Alzheimer's disease and related dementias among Ontario adults aged 65 years and older in 2010 and $2011 .^{8}$ Butt et al found an incidence rate of 2.7 per 10000 persons for parkinsonism among Ontario adults aged 20 years and older in $2010 .{ }^{10}$ Hudson et al reported an age-adjusted incidence of 2.6 per 100000 persons for ALS among men from 12 counties in southwestern Ontario between 1978 and $1982 .^{11}$

In this study, workers in miscellaneous metal-primarily nickel-mines who held mining occupations were observed with elevated rates of Alzheimer's disease, who also contributed most cases in the elevated rate of Parkinson's disease among workers in rock and soil drilling occupations. Nickel has been found in airborne dust in Ontario underground nickel mines, ${ }^{22}$ which might be responsible for the suggested elevation. The nervous system is susceptible to nickel toxicity in which oxidative stress and cellular energy metabolism shift play a key role. ${ }^{23}$
Workers in mining occupations had an elevated rate of Alzheimer's disease, but this elevation was not observed for 'Alzheimer's and other dementias' in a longer follow-up period, which might be explained by accuracy in case ascertainment algorithms. Alzheimer's disease was ascertained using hospitalisation data only that may have a higher positive predictive value than the algorithm used for 'Alzheimer's and other dementias' which involves the use of physician billing records in addition to hospitalisation data. In turn, case ascertainment for 'Alzheimer's and other dementias' would have higher sensitivity, whereas it could also introduce some false positive cases, leading to outcome misclassifications and biasing estimates towards the null.

The suggested elevation in incidence rates of Alzheimer's and Parkinson's-related conditions among gold mine workers may relate to other mining exposures. McIntyre Powder, insoluble fine-sized metallic aluminium and aluminium compounds, was inhaled by Ontario gold and uranium miners since 1943 as prophylaxis against silicosis but was discredited and discontinued in $1979 .{ }^{24}$ Aluminium exposure is suspected in the development of neurodegenerative conditions. For example, a meta-analysis found that chronic exposure to aluminium from dietary and occupational sources was associated with an increased risk of Alzheimer's disease (OR 1.71, 95\% CI 1.35 to 2.18). ${ }^{25}$ However, a recent study using a cohort of approximately 36000 former Ontario underground miners found an association between selfreported McIntyre Powder exposure and Parkinson's (RR 1.34, 95\% CI 1.14 to 1.57 ) but not Alzheimer's disease (RR 0.96, $95 \%$ CI 0.83 to 1.11$){ }^{26}$

Diesel engine exhaust may also contribute to those elevated rates in this study. Diesel engine emissions are an important component of total outdoor fine particles ${ }^{27}$ and have been a common exposure at Ontario underground metal mines since the 1960s. ${ }^{12}$ Further, the level of diesel exhaust exposure is considered higher in mining and its related activities than other industries $^{28}$ and the ambient environment. ${ }^{27}$ Ontario mining sites were found to have high diesel exhaust exposures, although levels have declined over time. ${ }^{29}$ Several studies have shown positive links between diesel exhaust exposure and neurodegenerative disease. A positive association was found between environmental fine particulate matter exposure and dementia 


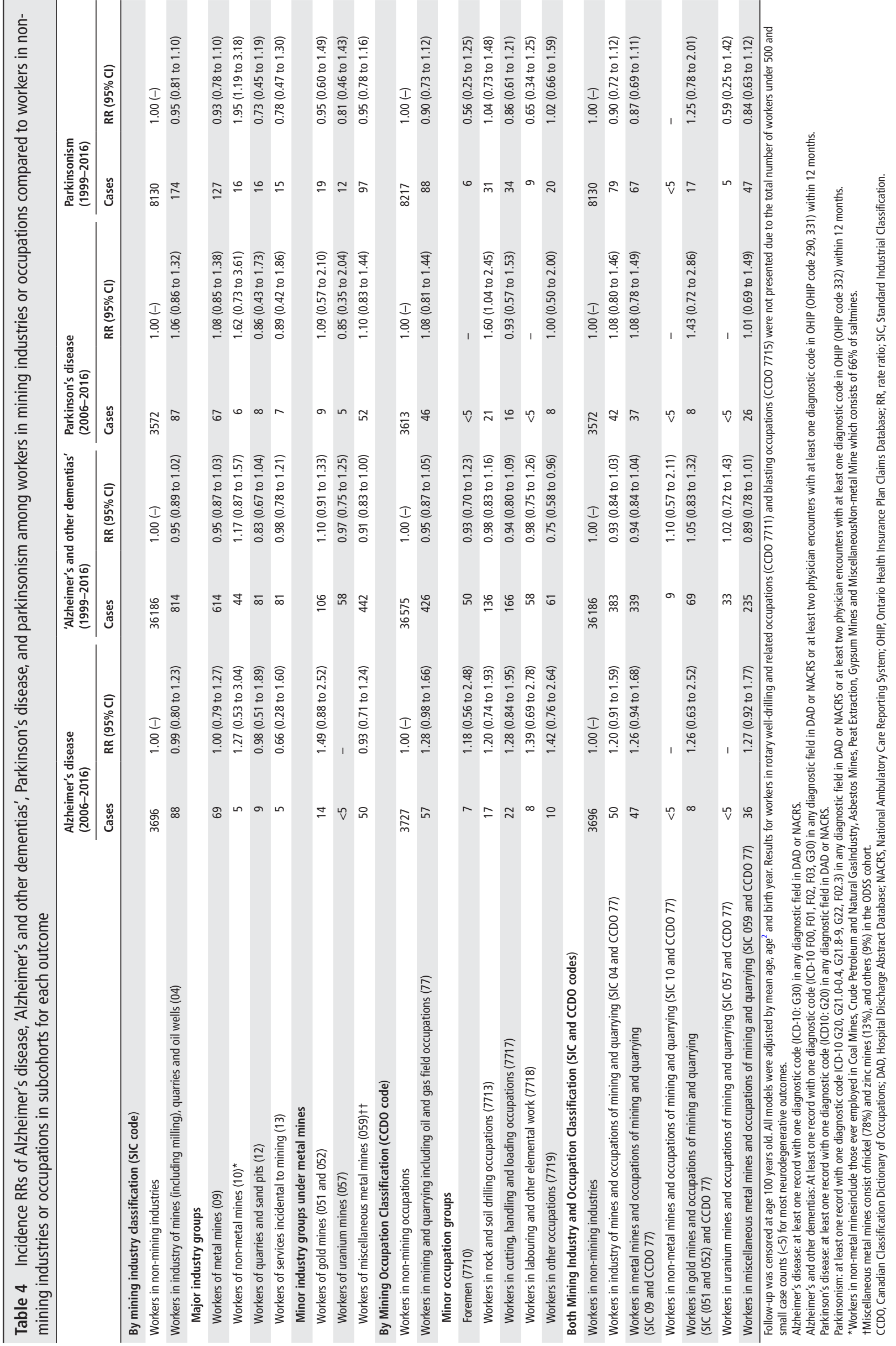


Table 5 Incidence RRs of motor neuron disease and amyotrophic lateral sclerosis among workers in mining industries or occupations compared to in non-mining industries or occupations in subcohorts for each outcome

\begin{tabular}{|c|c|c|c|c|}
\hline & \multicolumn{2}{|c|}{ Motor neuron disease (2006-2016) } & \multicolumn{2}{|c|}{ Als (2012-2016) } \\
\hline & Cases & RR $(95 \% \mathrm{Cl})$ & Cases & $\mathrm{RR}(95 \% \mathrm{Cl})$ \\
\hline \multicolumn{5}{|l|}{ By mining industry classification (SIC code) } \\
\hline Workers in non-mining industries & 570 & $1.00(-)$ & 247 & $1.00(-)$ \\
\hline Workers in industry of mines (including milling), quarries and oil wells (04) & 15 & $1.32(0.79$ to 2.20$)$ & 9 & $1.94(1.00$ to 3.78$)$ \\
\hline \multicolumn{5}{|l|}{ Major industry groups } \\
\hline Workers in metal mines (09) & 13 & 1.62 (0.94 to 2.81$)$ & 7 & 2.21 (1.04 to 4.69$)$ \\
\hline \multicolumn{5}{|l|}{ By mining occupation classification (CCDO code) } \\
\hline Workers in mining occupations & 576 & $1.00(-)$ & 252 & $1.00(-)$ \\
\hline Workers in mining and quarrying, including oil and gas field occupations (77) & 9 & $1.46(0.75$ to 2.82$)$ & $<5$ & - \\
\hline \multicolumn{5}{|l|}{ Both mining industry and occupation classification (SIC and CCDO codes) } \\
\hline Workers in industry of mines and occupations of mining and quarrying (SIC 04 and CCDO 77) & 9 & $1.65(0.86$ to 3.2$)$ & $<5$ & - \\
\hline Workers in metal mines and occupations of mining and quarrying (SIC 09 and CCDO 77) & 9 & $1.96(1.01$ to 3.79$)$ & $<5$ & - \\
\hline
\end{tabular}

Follow-up was censored at age 100 years old. All models were adjusted by mean age, age, $^{2}$ and birth year. Results for subgroups of the mining industry and occupation classifications were all suppressed due to small $(<5)$ numbers of case counts. Motor neuron disease: At least one record with one diagnostic code (ICD10: G12.2) in any diagnostic field in DAD or NACRS. Amyotrophic later sclerosis: At least one record with one diagnostic code (ICD10: G12.20) in any diagnostic field in DAD or NACRS. CCDO, Canadian Classification Dictionary of Occupations; DAD, Hospital Discharge Abstract Database; NACRS, National Ambulatory Care Reporting System; OHIP, Ontario Health Insurance Plan Claims Database; ; SIC, Standard Industrial Classification.

incidence among Ontario residents. ${ }^{30}$ In a Dutch populationbased cohort study, exposing to the high level of occupational diesel motor emission, compared with the environmental background level, was suggested to be associated with elevated mortality of Parkinson's disease (adjusted HR 1.37, 95\% CI 0.78 to 2.39$).{ }^{31}$ From a Danish case-control study, men with diesel exhaust exposure were more likely to have ALS than those unexposed when exposure was lagged for 10 years (adjusted OR $1.20,95 \%$ CI 1.05 to 1.38$)^{32}$

\section{Strengths and limitations}

This study is the first to examine incidence rates for common neurodegenerative diseases among miners in Canada. The ODSS cohort includes workers with accepted claims of work-related lost-time injuries or disease and allows comparisons between mining workers and workers of other high-risk industries and occupations, which reduces comparability issues related to socioeconomic characteristics and healthy worker biases involved with general population referents.

A significant strength of this study is the usage of Ontario administrative databases in identifying incident cases of neurodegenerative outcomes. Previous studies that ascertained cases from mortality data from death certificates ${ }^{31} 33$ are more liable to underreporting and outcome misclassification. Statistically precise RR estimates with more than 20 cases for the majority of groups were generated for 'Alzheimer's and other dementias' and parkinsonism, although relatively fewer cases were seen for Alzheimer's and Parkinson's disease, and rare conditions such as motor neuron disease.

The present study has several limitations. The ODSS cohort consists of working populations who were primarily compensated for musculoskeletal injuries, which may introduce selection bias if these injured workers had systematically different exposure or other risk factors than non-injured workers of the target population. Also, only male mining workers were included in the analysis, which limits our findings' generalisability to female mining workers. Besides, the ODSS cohort was established from a claimant database that did not include full work histories, individual exposure information, some demographic information such as race, ethnicity, and geographic locations, limiting the assessment of exposures to occupation and industry groups when the claim was filed, as well as limiting our ability to adjust for other exposures and demographic factors.

The magnitude and duration of exposures such as diesel engine exhaust might vary for different mining groups but were not available in this study. Systems used to classify these occupation and industry groups were limited to SIC-1970 and CCDO-1970, ${ }^{17}$ which does not allow direct identification for some large groups such as nickel mines. The SIC industry classification could not directly differentiate nickel-copper, one of the primary ores mined in Ontario, from miscellaneous metal mines.

In the ODSS, employment is considered at one point in time; this does not account for workers who changed their industry after their claim date that could lead to non-differential exposure misclassification. Combined effects from having mining employment or exposures from multiple industries among individuals who moved across ore and job types and filed multiple claims were not considered in this analysis.

This study could not capture cases that occurred before administrative databases were available, that is, before 1999 for physician billing records, 2006 for hospital discharge and ambulatory care data, and 2012 for ALS. These missed cases likely introduced non-differential outcome misclassification for both workers in mining and non-mining industries or occupations, which would have biased our RR estimates towards the null value. Another issue was the inability of the diagnostic code in physician claims to differentiate Alzheimer's disease from other cerebral degenerations, and therefore, false-positive cases may be included. Lastly, this study was limited to using ICD codes collected in administrative databases to ascertain neurological diseases. However, information on whether physicians applied the same criteria in diagnosing a specific neurological disease is unavailable; even if the same criteria were used, some widely used diagnostic criteria for Alzheimer's disease, Parkinson's disease and ALS demonstrated varied sensitivity ( 50\%-100\%) and specificity ( 30\%-100\%) from available studies. ${ }^{34-39}$

\section{CONCLUSIONS}

Our findings suggest elevated incidence rates of motor neuron disease among workers in metal mines, Alzheimer's disease among workers within miscellaneous metals mines and gold mines, and Parkinson's disease among workers within gold 
mines and rock and soil drilling occupations. Mining exposures such as nickel, McIntyre Powder (aluminium) and diesel engine exhaust might contribute to these elevations. More occupational cohort studies with assessments on these mining exposures as potential risk factors for neurodegenerative diseases is needed.

Contributors XZ, NLD and PAD planned the study. XZ conducted all analyses and drafted the manuscript. NLD assisted in the analyses and provided critical review of the manuscript. AMH, VHA and PAD provided direction on the study design, assisted the interpretation of results and provided critical review of the manuscript.

Funding This project was funded by Ontario's Ministry of Labour, Training and Skills Development (\#14-R-29 R-29), and the Public Health Agency of Canada (\#1516-HQ000066).

\section{Competing interests None declared.}

\section{Patient consent for publication Not required.}

Ethics approval This study obtained ethics approval from the University of Toronto Health Sciences Research Ethics Board (protocol number 39013).

Provenance and peer review Not commissioned; externally peer reviewed. Data availability statement Certain data are available on reasonable request. Supplemental material This content has been supplied by the author(s). It has not been vetted by BMJ Publishing Group Limited (BMJ) and may not have been peer-reviewed. Any opinions or recommendations discussed are solely those of the author(s) and are not endorsed by BMJ. BMJ disclaims all liability and responsibility arising from any reliance placed on the content. Where the content includes any translated material, BMJ does not warrant the accuracy and reliability of the translations (including but not limited to local regulations, clinical guidelines, terminology, drug names and drug dosages), and is not responsible for any error and/or omissions arising from translation and adaptation or otherwise.

ORCID iD

Xiaoke Zeng http://orcid.org/0000-0003-1813-1159

\section{REFERENCES}

1 GBD 2016 Neurology Collaborators. Global, regional, and national burden of neurological disorders, 1990-2016: a systematic analysis for the global burden of disease study 2016. Lancet Neurol 2019;18:459-80.

2 Canadian Institute for Health Information. The burden of neurological diseases, disorders and injuries in Canada. Ottawa: $\mathrm{CIHI}, 2007$.

3 Demers PA. Role of occupational studies in expanding our knowledge of environmental carcinogens International Society of exposure science and the International Society for environmental epidemiology joint annual meeting (ISESISEE). Ottawa, Canada, 2018.

4 Gunnarsson L-G, Bodin L. Occupational exposures and neurodegenerative diseases - a systematic literature review and meta-analyses. Int J Environ Res Public Health 2019:16:337.

5 Nowrouzi-Kia B, Gohar B, Casole J, et al. A systematic review of lost-time injuries in the global mining industry. Work 2018;60:49-61.

6 IARC. List of classifications, Volumes 1-123 IARC Monographs on the evaluations of carcinogenic risks to humans international agency for research on cancer 2013.

7 CAREX Canada. Mining sector: occupational exposure summary package https:// www.carexcanada.ca/CAREX_Mining_Package_July-16-2015.pdf

8 Jaakkimainen RL, Bronskill SE, Tierney MC, et al. Identification of Physician-Diagnosed Alzheimer's disease and related dementias in population-based administrative data: a validation study using family physicians' electronic medical records. J Alzheimers Dis 2016;54:337-49.

9 Government of Canada. Mapping connections: an understanding of neurological conditions in Canada - scope (prevalence and incidence) a partnership between neurological health charities Canada, the public health agency of Canada, health Canada and the Canadian Institutes of health research; 2014

10 Butt DA, Tu K, Young J, et al. A validation study of administrative data algorithms to identify patients with parkinsonism with prevalence and incidence trends. Neuroepidemiology 2014;43:28-37.

11 Hudson AJ, Davenport A, Hader WJ. The incidence of amyotrophic lateral sclerosis in southwestern Ontario, Canada. Neurology 1986;36:1524.

12 Industrial Disease Standards Panel. Report to the Workers' Compensation Board on Lung Cancer in the Hardrock Mining Industry. Toronto, Ontario: Industrial Disease Standards Panel (IDSP), 1994.
13 Muller J, Wheeler WC, Gentleman JF. Study of mortality of Ontario miners 1955-1977, Part I: Ontario Ministry of Labour, Ontario Workers' Compensation Board. Atomic Energy Control Board of Canada, 1983.

14 Natural Resources Canada. Minerals and metals fact books 2012-2017. Ottawa, Ontario: Natural Resources Canada (NRCan), 2017.

15 Jung JKH, Feinstein SG, Palma Lazgare L, et al. Examining lung cancer risks across different industries and occupations in Ontario, Canada: the establishment of the occupational disease surveillance system. Occup Environ Med 2018;75:545-52.

16 Shakik S, Arrandale V, Holness DL, et al. Dermatitis among workers in Ontario: results from the occupational disease surveillance system. Occup Environ Med 2019;76:625-31.

17 CAPS-Canada. An online tool to assist in coding of occpations and economic sectors. Available: https://ssl3.isped.u-bordeaux2.fr/CAPS-CA/Langue.aspx

18 Ontario Ministry of Health and Long-Term Care, Health System Information Management and Investment Division, Health Analytics Branch. The health analyst's toolkit. Ontario Ministry of Health and Long-Term Care, Health System Information Management and Investment Division, Health Analytics Branch, 2012.

19 Canadian Institute for Health Information. Canadian coding standards for ICD-10-CA and $\mathrm{CCl}$ Canadian coding standards evolution chronicle. Available: https://secure. cihi.ca/estore/productSeries.htm?locale=en\&pc=PCC189\&_ga $=2.134122698$. 574603051.1600712258-1585166381.1600712258

20 Ontario Ministry of Health and Long-Term Care. Resource manual for physicians: 4.15 diagnostic codes. Toronto, Ontario: Ontario Ministry of Health and Long-Term Care, 2017.

21 Statistics Canada. Table 17-10-0005-01, population estimates on July 1st, by age and sex

22 Industrial Disease Standards Panel. Occupational disease issues about Lung Cancer in the Hardrock Mining Industry IDSP Report. 128. Toronto, ON: Workers' Compensation Board of Ontario, 1994.

23 Song X, Fiati Kenston SS, Kong L, et al. Molecular mechanisms of nickel induced neurotoxicity and chemoprevention. Toxicology 2017:392:47-54.

24 Jacob A. Aluminium therapy and silicosis prevention II-Engineering aspects. The Canadian Institute of Mining and Metallurgy, 1947: 68-83.

25 Wang Z, Wei X, Yang J, et al. Chronic exposure to aluminum and risk of Alzheimer's disease: a meta-analysis. Neurosci Lett 2016;610:200-6.

26 Occupational Cancer Research Centre. Investigation of McIntyre powder exposure and neurological outcomes in the mining master file cohort: final report, 2020. Available: https://www.wsib.ca/sites/default/files/2020-05/mcintyrepowder_ocrc_finalreport_ apr3020b.pdf

27 CAREX Canada. Diesel engine exhaust environmental exposures https://www. carexcanada.ca/profile/diesel_engine_exhaust-environmental-exposures/

28 Diesel engine exhaust occupational exposures, 2020. Available: https://www. carexcanada.ca/profile/diesel_engine_exhaust-occupational-exposures/

29 Staskus G, Labour Mof. Underground diesel survey outcomes 2017 mining health and safety conference. 2014. Sudbury, Ontario: Ontario Ministry of labour, Occupational Health and Safety Branch, 2014.

30 Chen $\mathrm{H}$, Kwong JC, Copes $\mathrm{R}$, et al. Exposure to ambient air pollution and the incidence of dementia: a population-based cohort study. Environ Int 2017;108:271-7.

31 Brouwer M, Koeman T, van den Brandt PA, et al. Occupational exposures and Parkinson's disease mortality in a prospective Dutch cohort. Occup Environ Med 2015;72:448-55.

32 Dickerson AS, Hansen J, Gredal 0, et al. Amyotrophic lateral sclerosis and exposure to diesel exhaust in a Danish cohort. Am J Epidemiol 2018;187:1613-22.

33 Peters S, Reid A, Fritschi L, et al. Long-term effects of aluminium dust inhalation. Occup Environ Med 2013;70:864-8.

34 Knopman DS, DeKosky ST, Cummings JL, et al. Practice parameter: diagnosis of dementia (an evidence-based review). Report of the Quality Standards Subcommittee of the American Academy of Neurology. Neurology 2001;56:1143-53.

35 Hughes AJ, Daniel SE, Kilford L, et al. Accuracy of clinical diagnosis of idiopathic Parkinson's disease: a clinico-pathological study of 100 cases. J Neurol Neurosurg Psychiatry 1992:55:181-4

36 Hughes AJ, Daniel SE, Lees AJ. Improved accuracy of clinical diagnosis of Lewy body Parkinson's disease. Neurology 2001:57:1497-9.

37 Bhidayasiri R, Reichmann H, Roongroj B. Different diagnostic criteria for Parkinson disease: what are the pitfalls? I Neural Transm 2013;120:619-25.

38 Geevasinga N, Loy CT, Menon P, et al. Awaji criteria improves the diagnostic sensitivity in amyotrophic lateral sclerosis: a systematic review using individual patient data. Clin Neurophysiol 2016;127:2684-91.

39 Johnsen B, Pugdahl K, Fuglsang-Frederiksen A, et al. Diagnostic criteria for amyotrophic lateral sclerosis: a multicentre study of inter-rater variation and sensitivity. Clin Neurophysiol 2019;130:307-14. 